\title{
Lying Aversion, Lobbying, and Context in a Strategic Communication Experiment
}

\author{
William Minozzi* \\ Ohio State University \\ Jonathan Woon ${ }^{+}$ \\ University of Pittsburgh
}

December 2012

Forthcoming at Journal of Theoretical Politics

\begin{abstract}
Almost all institutions within modern democracies depend on a mix of communication and competition. However, most formal theory and experimental evidence ignores one of these two features. We present a formal theory of communicative competition in which senders vary in their aversion to lying, and test hypotheses from this theory using a strategic communication experiment. To influence lying aversion, we compare a Context Condition, in which pre-play instructions are cast in political language, with a Baseline Condition, in which all language is abstract. We find that in early rounds of play, subjects in the Context Condition exaggerated more as a function of their biases than those in the Baseline Condition when we control for the past history of play. But by the last round of play, subjects in both conditions converged on persistent exaggeration. This finding indicates that competition crowds out lying aversion in settings of strategic communication.
\end{abstract}

\footnotetext{
* Assistant Professor, Department of Political Science, 2137 Derby Hall, Ohio State University, Columbus, OH 43210. Phone: 614-247-7017. Email: minozzi.1@osu.edu

${ }^{+}$Associate Professor, Department of Political Science and Faculty, Pittsburgh Experimental Economics Laboratory, 4600 Wesley W. Posvar Hall, University of Pittsburgh, Pittsburgh, PA 15260. Phone: 412-648-7266. Email: woon@pitt.edu.
} 
Communication and competition are the connective tissues of modern democracy. Nearly every democratic institution seeks to resolve some collective choice problem by dividing the responsibilities of governing among branches of government, elites and the public, candidates and the electorate, advocates and judges, lobbyists and legislators, experts and decisionmakers. These divisions do not—indeed cannot—eliminate collective choice problems. Instead, they are transmuted into problems of agency and information transmission. The separated institutions are then tethered back to each other by sinews of communicative competition, in which interested actors send competing messages to uninformed, yet empowered agents.

Despite its theoretical and practical importance, our understanding of communicative competition is severely limited. Communication in non-competitive strategic settings is well understood in comparison. In the basic strategic information transmission (SIT) model, a lone sender can only credibly send coarse, categorical messages even if she has access to fine-grained details (Crawford and Sobel1982; Gilligan and Krehbiel 1987). Dozens of studies have applied this single-sender model to democratic politics, even though politics in democratic institutions is almost always competitive. Bankers battle consumer advocates to influence financial regulation, scientists skirmish with skeptics to convince the public whether climate change is a problem worthy of public attention, petitioners confront the government over issues of equal protection and civil liberties, and the president clashes with congressional opposition to persuade the median legislator to support prudent fiscal policy. Competition between competing, informed interests is pervasive. Ignoring this facet of the political world would not be so bad if it were not the case that theoretical predictions for an isolated sender can differ markedly 
from those of competing senders. For example, competing senders with private information about their preferences can either reveal their information or jam, directly countering the information broadcast by her opponent (Minozzi 2011).

As underdeveloped as our theoretical understanding of communicative competition is, our empirical understanding is even worse. Very few studies analyze multi-sender SIT experiments. ${ }^{1}$ Single-sender SIT experiments are plentiful by comparison (e.g., Blume et al. 1998; Crawford 1998; Dickhaut, McCabe, and Mukherji 1995; Gneezy 2005; Lupia and McCubbins 1998), although findings from these experiments have not faithfully replicated equilibrium predictions. In fact, the fundamental single-sender SIT problem - the lack of credible communication-is substantially reversed in the lab, in a phenomenon called overcommunication, which occurs when senders reveal more information about the underlying truth than the theory predicts (Blume et al. 2001; Cai and Wang 2006). In other words, where the theory predicts that messages reveal only categorical information (e.g., that the truth is "high" or "low"), laboratory subject instead use messages that reveal finer-grained details (e.g., messages that vary continuously with the truth). It remains an open question whether such overcommunication will be evident in the multi-sender SIT experiments that more closely resemble democratic politics.

The prevailing theoretical explanation for overcommunication is pro-social preferences (Hurkens and Kartik 2009; Sánchez-Pagés and Vorsatz 2007, 2009). For example, subjects might be simply be averse to lying. But explanations based on pro-social preferences implicitly assume that individuals have fixed preferences that are not

${ }^{1}$ There are a few exceptions. In a companion paper (Minozzi and Woon, n.d.), we test the equilibrium predictions from Minozzi (2011). Also see Boudreau and McCubbins (2008) and Dickson, Hafer, and Landa (2008) for related studies. 
situation-specific. Thus, some individuals may be more averse to lying than others. However, it is not clear how such pro-social preferences will manifest in settings with communicative competition. Moreover, an experimenter cannot simply manipulate pro-social preferences as she might with payoffs.

One possibility is to take advantage of the idea that pro-social preferences depend on context (Levitt and List 2007). While we cannot directly manipulate pro-social preferences, we can attempt to indirectly influence them by priming subjects. In so doing, we can then learn how pro-social preferences and competition interact in a strategic communication setting.

In this paper, we develop a formal theory of communicative competition with private information about preferences and lying aversion. After deriving equilibrium predictions, we present several experimental hypotheses about the role of pro-social in communicative competition. Our main design contribution is to use the relationship between context and pro-social preferences to learn about how the latter interact with competition. To do so, we formulate several hypotheses based on the formal theory. We then test these hypotheses with an experiment in which we manipulate context.

The focal treatment in the experiment is a priming and labeling manipulation. Subjects in all sessions play a communicative competition game with an identical strategic and payoff structure. In the Baseline Condition, all labels are abstract (e.g., "Player A"). In the Context Condition, all labels are political (e.g., "Lobbyist A"), and subjects read a short paragraph about lobbying and the unknown incentives of lobbyists before play begins. We find that subjects in the Context Condition exaggerate more initially as a function of their biases, but that after many rounds, play in the two conditions converges. Based on this 
finding, we argue that lying aversion has very different consequences in competitive environments than in single-sender environments. With repeated play, it appears that competitive incentives crowd out initial aversion to lying, as overcommunication is transmuted into persistent exaggeration.

\section{Theory and Hypotheses}

In this section, we develop a formal model of communicative competition with lying aversion and use it derive a set of testable hypotheses. But first consider the value of such an exercise. Pro-social preferences like lying aversion are inherently unobservable. If individuals do have preferences against lying, we cannot simply manipulate those preferences via monetary payoffs, as in standard economics-style experiments. Without the ability to manipulate lying aversion, how can we test any hypotheses?

This argument depends critically on the implicit assumption that pro-social preferences are hard-wired and do not vary with the context of the experiment. However, there is ample evidence that this assumption is false. For example, Ross and Robertson (2000) find that subjects who play a prisoners' dilemma game labeled as the "Wall Street" game defect at higher rates than those who play the same game labeled as the "Community Game." Burnham, McCabe, and Smith (2000) study trust games in which fellow subjects are labeled variously as "opponents" and "partners", finding that the latter are trusted more than the former. Indeed, priming and framing effects are well-known from and studied by the literature in political psychology. Therefore, if two sets of subjects play communicative competition games that are strategically equivalent but described differently, their lying aversion may well change. 


\section{Communicative Competition and Lying Aversion}

A simple formal theory of communicative competition involves two senders and one receiver. $^{2}$ Each sender learns the value of the target $T$ and sends a message to the receiver. The receiver does not observe the target but does make a choice that affects all the players. In addition to knowing the target, each sender also knows his own preferences. These preferences are based on the receiver's choice as well as the sender's message.

More formally, each sender $I \in\{L, R\}$ (privately) knows three things-the target $T$, his shift $S_{I}$, and his lying aversion function $\kappa_{I}(\cdot)$. He sends a message $m_{I} \in \mathrm{R}$ (the set of real numbers) to the receiver, who then chooses $c \in R$. Each sender's ideal point is $T+S_{I}$, the receiver has ideal point $T$, and the payoffs for each player depend on the distance between $c$ and ideal point. Thus, each sender's payoff includes the term $u_{I}=v\left(\left|c-\left(T+S_{I}\right)\right|\right)$, and the receiver's payoff includes $v(|c-T|)$, where $v(\cdot)$ is a decreasing, concave function. For simplicity of presentation, we focus on the quadratic-loss case $v(x)=-x^{2}$, but this is not necessary for any of the results.

Senders also prefer not to lie too egregiously. We assume that each sender has quasilinear utility over payoffs and lying aversion, and that this utility is $u_{I}+\kappa_{I}\left(\left|T-m_{I}\right|\right)$, where $\kappa_{I}(\cdot)$ is a decreasing, concave function. Therefore, we differentiate between a subject's payoffs controlled by the experimenter and the choices of the subjects, and a subject's utility, which includes payoffs as a component. For ease of illustration, we use the functional form ${ }_{I}\left(\begin{array}{ll}\mid m_{I} & T \mid ;{ }_{I}\end{array}\right)=\left(\begin{array}{lll}1 & { }_{I}\end{array}\right)\left(m_{I} \quad T\right)^{2} /\left(\begin{array}{ll}4_{I}\end{array}\right)$, where $\lambda_{I} \in(0,1]$, where $\lambda_{I}$ is a

\footnotetext{
${ }^{2}$ In our discussion male pronouns refer to senders, and female pronouns to receivers.
} 
player's lying tolerance. ${ }^{3}$ Lying costs are severe for $\lambda_{I}$ near 0 , and are negligible for $\lambda_{I}$ near 1 . This functional form of $\kappa_{I}(\cdot)$ permits a very simple representation of equilibrium message strategies based on the parameter $\lambda_{I}$.

Consider a simple, symmetric version of this game. The target $T$ is uniformly distributed on $[-100,100]$, one sender is on the left with $S_{L}$ distributed uniformly on $[-50,0]$, and the other is on the right with $S_{R}$ uniformly distributed on $[0,50]$. Thus, the average distance between the receiver's ideal point and each sender's is $S=E\left|S_{L}\right|=E\left|S_{R}\right|$. Lying tolerance $\lambda_{I} \in[0,1]$ is distributed according to a continuous, atomless distribution $F(\cdot ; \theta)$ with full support and expectation $\mu(\theta)$, for $\theta \in \Theta$, which represents the context in which players interact. All random variables are assumed to be independently distributed.

We assume that context affects the lying tolerance distribution in the following way:

Context Assumption. If $\theta^{\prime}<\theta$, then $\mu\left(\theta^{\prime}\right)<\mu(\theta), \forall \lambda \in[0,1]$.

The Context Assumption articulates the idea that the context in which actors engage affects their tolerance for lying. Many technical assumptions about the relationship between $F$ and $\theta$ yield the Context Assumption as a consequence. For example, if $F(\cdot ; \theta)$ first order stochastically dominates $F\left(\cdot ; \theta^{\prime}\right)$, the Context Assumption is satisfied.

We focus on perfect Bayesian equilibria. In equilibrium, messages are exaggerated away from the receiver's target. This exaggeration takes the form of a linear function of the

${ }^{3}$ Technically, assume $\kappa_{I}\left(\left|m_{I}-T\right| ; 0\right)=-\delta\left(\left|T-m_{I}\right|\right)$, the Dirac delta function. 
sender's shift. The receiver splits the difference between the messages she observes, choosing an action that is at the midpoint.

Equilibrium Characterization. For $\theta \in \Theta$, the strategies

$$
m_{L}^{*}=T+2 \lambda_{L} S_{L}-2 \lambda_{L} S A(\theta), \quad m_{R}^{*}=T+2 \lambda_{R} S_{R}+2 \lambda_{R} S A(\theta), \text { and } c^{*}=\frac{1}{2}\left(m_{L}+m_{R}\right)
$$

support an equilibrium, where $A(\theta)=\mu(\theta) /(1-\mu(\theta)) .^{4}$

To see why these strategies constitute an equilibrium, suppose the receiver splits the difference between the messages, as in $c^{*}$. Each sender balances the gains from exaggeration against his aversion to lying. Senders have two incentives to exaggerate their messages away from $T$. First, even if lying aversion was negligible $(\lambda=1)$ and a sender could choose a message that was directly implemented by the receiver, he would want to send the message $m_{I}=T+S_{I}$, which is exaggerated away from $T$ by $S_{I}$. This exaggeration is an example of the fundamental SIT problem identified by Crawford and Sobel (1982).

A second incentive for exaggeration is competition. Each sender compensates for the exaggeration he expects from his opponent. In fact, the equilibrium of this game is quite different if there is common knowledge of no lying costs. ${ }^{5}$ Senders who are averse to lying temper their messages, drawing them back toward $T$. Because senders have symmetrically distributed shifts and lying tolerances, the receiver does not know who lied

\footnotetext{
${ }^{4}$ See the appendix for a more complete description of the equilibrium, including receiver beliefs.

${ }^{5}$ When lying aversion is not a possibility, equilibria are characterized by jamming.
} 
more. As a result, her posterior expected value of $T$ is $E\left[T \mid m_{L}, m_{R}\right]=\frac{1}{2}\left(m_{L}+m_{R}\right)$, and so she splits the difference to maximize her payoffs.

We now consider how these strategies change as one alters the context of the experiment in light of the Context Assumption. Equilibrium message strategies are linear functions of target and shift. In these strategies, the slopes and intercepts depend not only on one's lying tolerance $\lambda$, but also the distribution of the lying tolerance. According to the Context Assumption, changes in context $\theta$ directly affect this distribution by increasing $\mu(\theta)$, the expected value of $\lambda$.

How would equilibrium message strategies change if the context parameter $\theta$ increases? We should expect exaggeration to increase for two reasons that are intimately related to the two incentives senders have to exaggerate their messages. The lying tolerance parameter $\lambda$ enters the equilibrium message strategies in both the slope on the shift and the intercept. First, the slope on the shift increases directly with $\lambda$, and so we have a clear prediction: as $\theta$ increases, so should the slope on shift.

The change of the intercept is similar, but also includes a second effect. Not only does the intercept of the equilibrium message strategy depend on $\lambda$, it also depends on $A(\theta)$, which is an increasing function of $\mu(\theta)$, the expectation of $\lambda$. Thus, not only does the (absolute value of the) intercept increase with $\lambda_{I}$ on average, the change in context increases the intercept directly through its increase on $A(\theta)$. Based this model of communicative competition with lying aversion, we next derive a series of hypotheses to test in the lab. 


\section{Hypotheses}

To derive hypotheses from this model, we combine its insights with well-known empirical regularities from experimental economics. First, the Context Assumption formalizes the idea that individuals' lying aversion depends in predictable ways on some well-known yet payoff-Irrelevant feature of the strategic environment. How might context change senders' behavior? It is possible that the change will be negligible. In a single-sender setting, Rode (2010) finds that senders behave no differently when they face receivers in competitive context than in a cooperative context. Alternatively, the equilibrium prediction of the formal model is that senders should exaggerate more in a Context Condition that diminishes the expected cost of lying relative to a Baseline Condition.

Context Hypothesis. Subjects in the Context Condition will exaggerate more than subjects in the Baseline Condition. Specifically, the coefficient on shift and the absolute values of the intercepts should all be larger in the Context Condition.

A second question is how durable the effects of context might be if subjects play the game multiple times. In our model, context acts via two mechanisms. First, one's own aversion to lying is assumed to be context dependent. Second, one's beliefs about others' aversion to lying is assumed to be context dependent (see also Dufwenberg, Gachter, and Hennig-Schmidt 2011).

In the lab, however, both mechanisms may fade with repeated play. To see why, consider a finitely repeated version of the game in which players behave myopically. This description is very close to the experiment that follows, in which players are randomly and anonymously matched with each other as they play the game repeatedly. Such a finitely 
repeated game also matches the empirical reality of large, diffuse political-economic markets like that for lobbyists. The setting is well-modeled as a sequence of single-shot games, each with a slightly different context. As subjects play the game repeatedly, the relative information conveyed by the original context fades in comparison with the growing context of past play. Our formal model captures only a single play of the game. The contexts of the two conditions are likely to be more similar during the $n^{\text {th }}$ round of play than during the $(n-1)^{\text {th }}$. Indeed, Blume et al (2001) study a single-sender environment, comparing a condition with meaningless messages and a condition with messages that have a priori meaning, and they find that initial meanings tend to deteriorate over time. Therefore, we hypothesize that context effects will decay with repeated play.

Decay Hypothesis. After many rounds of the game, subjects in both conditions will converge on similar strategies.

As we take this model to the lab, we utilize a pair of contexts that is very likely to satisfy this assumption. Lobbyists are associated with lying. In a recent survey, respondents were asked to "rate the honesty and ethical standards" of people in different fields. 61\% put lobbyists in the "low" or "very low" categories, while only 7\% put them in the "high" and "very high" categories. ${ }^{6}$ While $61 \%$ is far from complete saturation, it is plausible that the $39 \%$ who believe lobbyists to be average or better when it comes to "honesty and ethical standards" are still aware of this negative professional reputation, and allow it to affect their second-order beliefs.

6 This Gallup poll from November 2010 was accessed from the website of the Roper Center at the University of Connecticut, USGALLUP.10NM19.R03V. 
To leverage the apparently widespread belief that lobbyists are less averse to lying than others, we had subjects play a communicative competition game in two different conditions. The conditions only differ in the instructions that subjects were given. In our Baseline Condition, players' roles were given abstract names (e.g., "Player A"). In our Context Condition, subjects play a strategically equivalent game but with descriptive role names (e.g., "lobbyist A"). The Context Condition also included a short paragraph that described the relationship between legislators and lobbyists in general terms, emphasizing that, "Legislators, however, do not always know whether it is in the best interests of lobbyists to tell the truth." The complete paragraph appears in the next section.

\section{Experimental Procedures}

We conducted experiments at the Pittsburgh Experimental Economics Laboratory at the University of Pittsburgh. Subjects were recruited using the lab's database; most were undergraduates at the University of Pittsburgh. No subjects from the authors' classes were recruited, and each subject participated in only a single session.

We used z-tree (Fischbacher 2007) to construct the experimental environment. After arriving at the lab, subjects gave informed consent and sat at individual computers. All interactions among subjects were computer-mediated and anonymous. Instructions were read out loud, presented on computer screens, and distributed in printed form so that subjects could refer to them as often desired. ${ }^{7}$ Subjects were clearly instructed not to communicate during the session and were given a quiz on their computers about the

${ }^{7}$ Instructions appear in the appendix. 
instructions. Upon completion, subjects received immediate, private feedback about whether they answered questions correctly and explanations of the correct answers. Consistent with lab policy, no deception or false feedback was used in the experiment. Next, the software randomly assigned each subject to a role. In our Baseline Condition, the instructions only referred to the roles as "Player A," "Player B," and "Player $\mathrm{C}^{\prime \prime}$, for the left sender, right sender, and receiver, respectively. In the Context Condition, these role labels were replaced with the labels "Lobbyist A," "Lobbyist B," and "the Legislator." Subjects then played 24 to 32 rounds of the game (depending on the session). ${ }^{8}$ Roles were fixed throughout the session.

At the beginning of each round, subjects were randomly matched (with replacement) into groups, one subject per role per group. To avoid reputation effects, subjects had no identifying information about the other group members in any round. After group composition, targets $T$ and shifts $S_{L}$ and $S_{R}$ were drawn. To match the model above as closely as possible, $T$ was drawn uniformly from the integers between -100 and 100 , the right sender's shift $S_{R}$ was drawn uniformly from integers between 0 and 50, and left sender's shift $S_{L}$ was drawn uniformly from integers between -50 and 0 . Throughout the experiment, we referred to each player's ideal action as her "target." For example, in the Baseline Condition, $T$ is referred to as "C's target," $T+S_{L}$ is "A's target," and $T+S_{R}$ is "B's target." In the text, we continue to use the terms "target" and "shift" as above.

Our goal was to convey the political environment of a spatial model as effectively as

${ }^{8}$ Appendix Table A-1 provides summary statistics on the sessions. 
possible. As such, we used a very large number of targets, shifts, and actions. To ensure an even distribution of targets and shifts, we use a stratified sampling technique that divides the target set into 8 subsets and each shift set into 2 subsets, for a total of 32 strata. The draw for each round corresponds to one of these strata. The order of the strata was randomized in each session so that, from the subjects' point of view, the targets and shifts were distributed as described above. Although the target, shift, and action sets are technically discrete, they are large when compared with previous experiments on cheap talk games, which typically involve small state spaces (e.g., 4 states in Dickhaut, McCabe, and Mukherji 1995 and 5 states in Cai and Wang 2006). We use the large state space to more effectively instantiate the spatial model in our experimental environment. This goal is also advanced with our computer interface, which used both text and graphics to present information (see Appendix Figure A1). This display helps to reinforce the idea that the setting is effectively spatial.

After creating groups and selecting targets and shifts, each sender simultaneously observes the target and his own target (i.e., $T+S_{I}$ ). He then chooses a message to send to the receiver. Our interface displays potential messages on a horizontal axis, and to send a message, a sender uses the mouse to drag a slider along the horizontal axis to his desired message (between -150 and 150). In addition to these messages, the interface also displays the range of possible targets, the realized target, the ranges of possible targets for the senders, and the sender's own target. ${ }^{9}$ The receiver observes messages from both senders simultaneously, via a similar display. The receiver then drags a slider to choose an

\footnotetext{
9 The sender's interface also has a payoff calculator to show the sender's and receiver's payoffs for each possible action the receiver might choose.
} 
action between -150 and 150 . At the end of each round, subjects see the results from that round for their group: both messages and the action, and every player's target and payoffs. Subjects also see the results from all previous rounds they played, although they do not see the results for groups to which they did not belong.

Per round payoffs were denominated in points, and the maximum possible points a player could earn in a round was 100 . The receiver's payoff was $100-|c-T|$, and each sender's payoff was $100-\left|c-\left(T+S_{I}\right)\right|$. At the end of the session, total points were converted to cash, $\$ 1$ for 150 points. Subjects were also paid a $\$ 7$ participation payment.

Our Context Condition featured three changes to the experiment. First, the experiment was entitled, "The Lobbying Experiment," rather than, "The Experiment," as in the Baseline Condition. Second, all player labels were changed as indicated above. Senders were referred to as, "lobbyists," and receivers were referred to as, "legislators." Third, at the beginning of the experiment, the subjects read a short paragraph:

Senators and representatives vote on many different pieces of legislation covering many different facets of domestic and foreign policy. But they are not experts on everything. Some legislators learn about the details of these issues by talking to lobbyists, who can represent businesses, citizen groups, other countries, or many other interests. Legislators, however, do not always know whether it is in the best interests of lobbyists to tell the truth.

Next, we analyze the effects of this contextual prime.

\section{Empirical Analysis}

We conducted four sessions of the Baseline Condition and two of the Context Condition.

Each session involved between 15 and 18 subjects (5 to 6 groups), who played either 
24 or 32 rounds. Throughout the analyses that follow, our main dependent variable is each sender's Message. ${ }^{10}$ But first we provide a visual representation of the data from the experimental sessions. As a first cut control for the effect of Target on Message, we define Exaggeration as Target - Message for Left Senders and Message - Target for Right Senders. To see whether there are systematic differences between conditions at the individual level, Figure 1 displays a separate sparkline for each sender's messages, along with the minimum and maximum Exaggeration by subject. ${ }^{11}$ Senders are separated by condition (Baseline or Context). Numbers on the left (and down-pointing triangles) indicate minimum Exaggeration; numbers on the right (and up-pointing triangles) indicate maximum Exaggeration. The dashed horizontal lines demarcate zero, or no difference between Target and Message.

Relatively few subjects ever send a message on the "wrong" side of the Target in Figure 1 . That is, only 17 of our 66 subjects have negative values for minimum Exaggeration. ${ }^{12}$ For most subjects, there is also a tendency to exaggerate more in later

\footnotetext{
${ }^{10}$ We divide Target, Message, and Shift by 100 and Round by 32, so that coefficients are all on the same scale. See Appendix Table A-1 in for summary statistics.

${ }^{11}$ For simplicity, only senders who played 32 rounds are presented in the figure. The omission of those subjects does not alter any interpretations offered here.

${ }^{12}$ Using a similar figure and similar reasoning, we can provide initial evidence that subjects treated the Target as the truth rather than what is described in the instructions as "their Target" (i.e., Target + Shift). A theory that takes lying aversion as dependent upon the difference between Message and Target + Shift (i.e., $\left|m_{I}-\left(T+S_{I}\right)\right|$ rather than $\left|m_{I}-T\right|$ ) would predict that no player would ever send a Message between Target and Target + Shift. In our sessions, 44 out of 66 subjects sent such messages.
} 


\section{Exaggeration by Subject}

Left Senders

Baseline

$$
-1.39=
$$
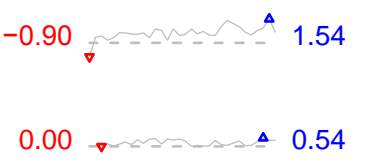

$0.02 \ldots 1.43$

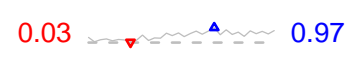

$0.04+21.16$

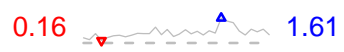

0.28

$\Delta 1.70$

0.29

1.13

0.43 - 1.38

0.46

1.68

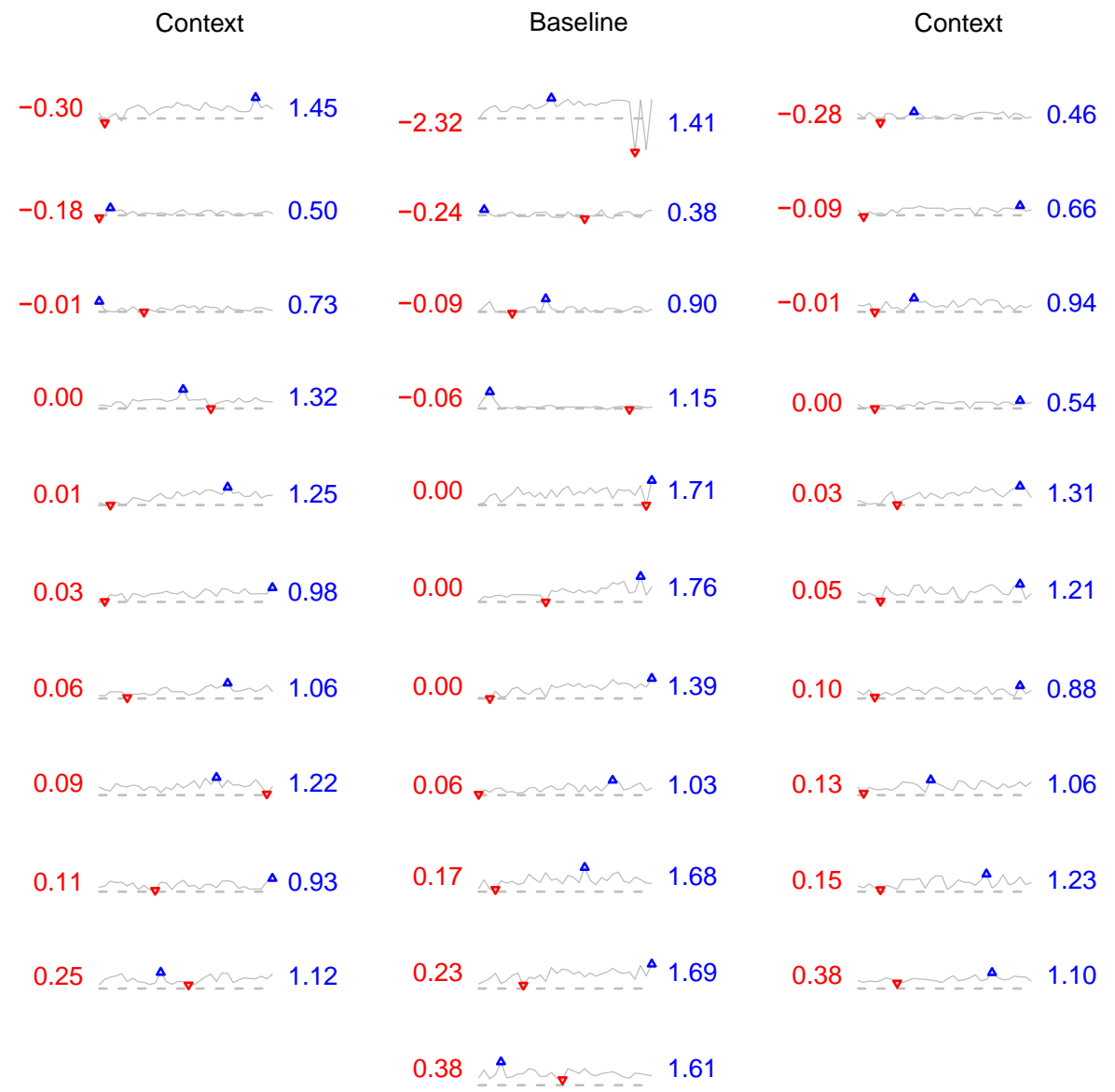

Figure 1: Exaggeration by Subject. Each sparkline represents the Exaggeration for a sender over a session. Exaggeration is $T-m_{L}$ for left senders and $m_{R}-T$ for right senders. The number to the left of a sparkline is the minimum Exaggeration for a subject, which is marked with a down triangle. The number on the right is the maximum Exaggeration, which is marked with an up triangle. All sparklines are presented on the same horizontal and vertical scales. For simplicity of presentation, only sessions with 32 rounds are presented. Results for those with 24 rounds are similar. 
rounds. Only 10 of 66 subjects sent their minimally exaggerated Message after their maximally exaggerated message.

But Figure 1 also reveals few if any differences between Exaggeration in the Baseline and Context Conditions, even after (crudely) controlling for Target. To test our hypotheses more carefully and systematically, we next report a series of multilevel (i.e., mixed effects) models. The dependent variable in each model is Message, and the predictors are Target, Shift, and separate intercepts for Left Sender and Right Sender. ${ }^{13}$ To control for subject- and round-level variation, each model includes varying intercepts and varying slopes by Subject and by Round. Our treatment is an indicator for the Context Condition. All reported tests are two-tailed.

The Context Hypothesis predicts different intercepts and slopes on Shift for the Baseline and Context Conditions. Therefore, we include the interaction of Context with each of Shift, Left Sender, and Right Sender in our first model. ${ }^{14}$ Relative to the Baseline Condition, in the Context Condition we expect the slope on Shift to be larger, the Left Sender intercept to be smaller, and the Right Sender intercept to be larger (i.e., intercepts should both be further from zero in the Context Condition).

The results from our first analysis are mixed (see Figure 2). On the one hand, the slope on Shift is, as predicted, somewhat larger in the Context Condition than the Baseline Condition, although this relationship is not significant ( $p=0.18$ ). On the other hand, the intercepts are actually both closer to zero in the Context Condition than in the Baseline Condition, in opposition to our expectations. But this model assumes that strategies do not

13 Therefore, we exclude a constant from these models.

14 See model [1] from Appendix Table A-2 for details. 


\section{Baseline Context}
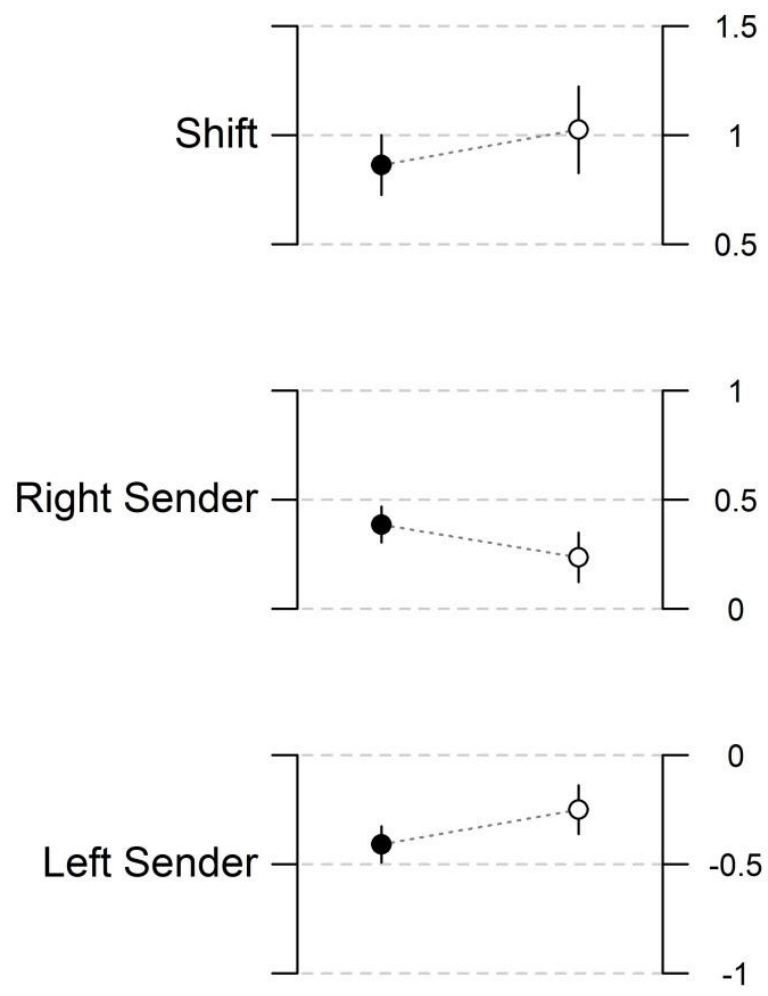

Figure 2: Context Effects. On average, the coefficient on Shift is larger in the Context Condition, as expected, but the intercepts on Left and Right Sender have the opposite sign from that predicted by the formal model. Estimates are based on a multilevel regression of Message on Shift, Left Sender, Right Sender, the interaction of each of those with Context, and Target. See model [1] from Appendix Table A-2 for details.

change over the course of the experimental session, despite our prediction in the Decay Hypothesis. It is therefore possible that this model obscures initial differences due to the context manipulation that may vanish by the final round. To test this hypothesis, we interact each predictor from our first model with the Round of play (see Appendix Table A-2 for details). ${ }^{15}$

${ }^{15}$ Round is rescaled by $1 / 32$. 

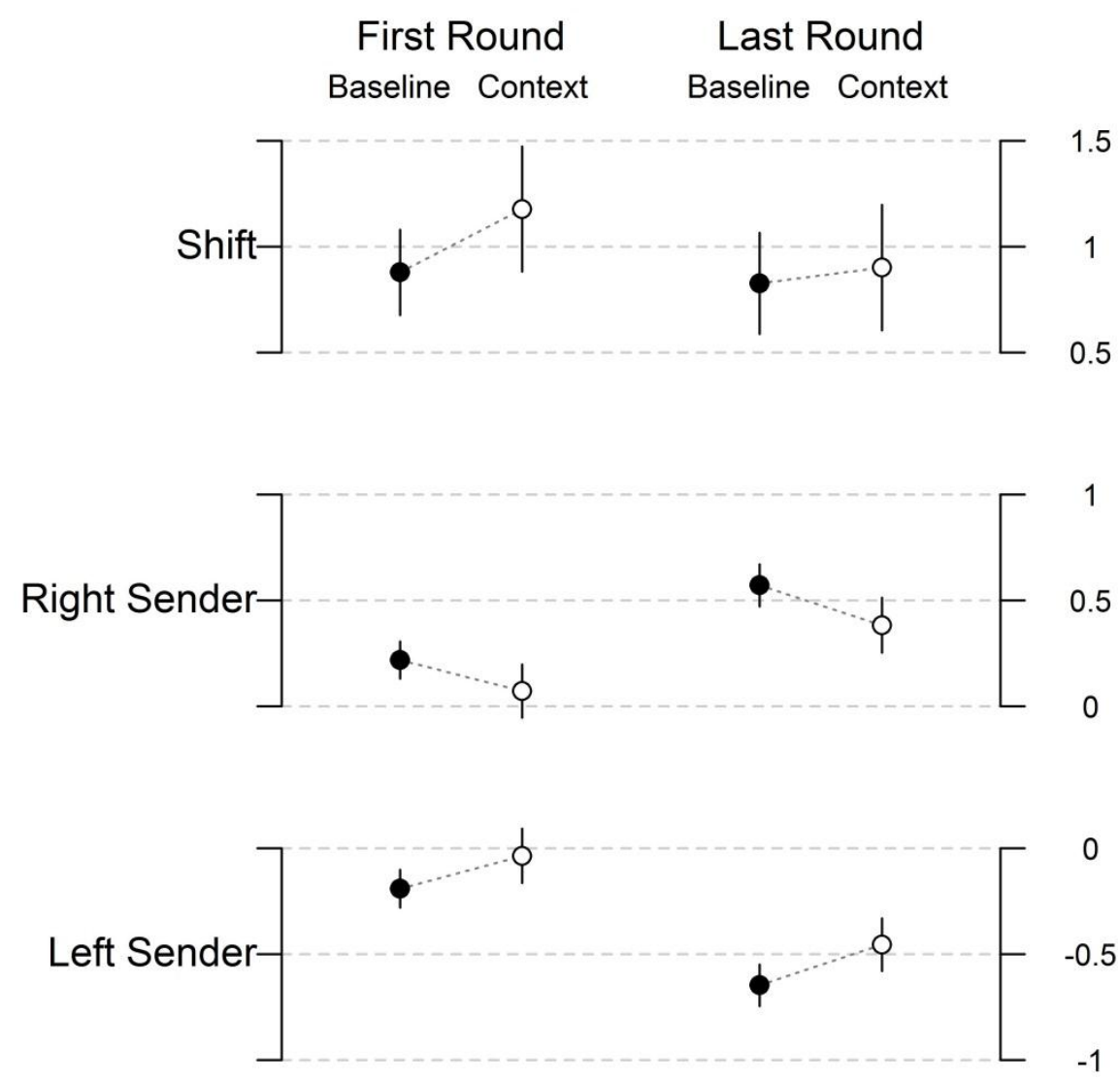

Figure 3: Duration of Context Effects. An initial difference in the slope on Shift diminishes by the last round. Drift over the course of play is also evident in the intercepts. But the earlier finding that intercepts are closer to zero in the Context Condition than in the Baseline Condition persists. Estimates are based on a multilevel regression of Message on Shift, Left Sender, Right Sender, the interactions of each with Context, Round, and Context $\times$ Round, with a control for Target. See model [2] from Appendix Table A-2 for details.

There is evidence of the Decay Hypothesis in the Shift coefficient, but the results for the intercepts remain at odds with the theoretical predictions (see Figure 3). First, once we condition on the Round of play, a somewhat stronger difference emerges between conditions. The Shift coefficient in the Context Condition is now larger than 0 , and this relationship is borderline significant ( $p=0.095$ ). However, by the last round this difference reverses. The point estimate of the Shift coefficient is actually lower in the 
Context Condition than in the Baseline Condition, although this difference is not significant. Moreover, not only are both the Left and Right Sender intercepts closer to zero in the Context Condition than in the Baseline Condition, these distances only seem to grow by the last round.

The results so far do not provide much support for the theoretical predictions. But the above analyses are predicated on the notion that subjects are abiding by the assumptions of equilibrium behavior, for if they are not the regression is misspecified. In particular, equilibrium analysis requires that (1) players use best response strategies and (2) players have beliefs and strategies that are mutually consistent. It is possible to relax one of these requirements while maintaining the other. The second requirement (mutual consistency) can be relaxed without jeopardizing the best response assumption. For example, we could assume that players' beliefs about others' behavior corresponds to their past experience, and that players then play best responses to those (potentially mistaken) beliefs. In a companion paper (Minozzi and Woon, n.d.), we find that such a framework of experiential best response provides a better explanation for how subjects play this communicative competition game. In the next section, we introduce this framework and apply it to the case at hand.

\section{Experiential Best Responses and Lying Aversion}

The idea behind experiential best response is that subjects develop expectations about each other's behavior based on their individual histories of play, rather than based on the strategies identified by equilibrium analysis. Such play would not be surprising. In fact, our experimental interface informs subjects of their past histories immediately after every round. If subjects use past history in their strategies, then the omission of that variable 
casts some doubt on the results of our previous analysis.

If senders condition their messages on their experience, then their beliefs will not necessarily match the strategies of their opponents. Suppose each sender expects his opponent to send the message $E_{I}\left[m_{-I}\right]=T+\bar{\xi}_{-I}$, where $\bar{\xi}_{-I}$ is the sender's expectation of his opponent's exaggeration. In the experiential best response framework, $\bar{\xi}_{-I}$ is assumed to be based on the sample average of the difference the sender has observed between past Targets and his opponents' Messages. If sender $I$ also believes the receiver's action will be the average of the messages she observes, then his best response will be the message $m_{I}^{E B R}=T+2 \lambda_{I} S_{I}-\lambda_{I} \bar{\xi}_{-I}{ }^{16}$

To apply this framework to our data, we estimate a multilevel model of Message that includes the variables from above (Target, Shift, Left Sender, Right Sender), as well as Opponent's Past Exaggeration, which, for a particular sender, is the average difference between his opponent's Message and Target over the past five rounds. ${ }^{17}$ We also interact Shift, Left Sender, Right Sender, and Opponent's Past Exaggeration with Context and Round.

This best response strategy has both similarities to and differences from the equilibrium message strategy. Like the equilibrium strategy, the experiential best response framework predicts a positive coefficient on Shift. However, unlike the equilibrium predictions, this framework predicts a negative coefficient on Opponent's Past Exaggeration, and a null intercept for each sender. Moreover, this framework also predicts

16 See Proposition 3 in the appendix for a proof.

17 For rounds 2-5, the experience of all previous rounds is coded as Opponent's Past Exaggeration. The first round is excluded. We also ran the analysis using the previous 10 and 15 rounds with no substantive changes. By conventional model selection criteria (e.g., AIC, deviance), the model with Opponent's Past Exaggeration based on the past five rounds offers the best fit. 
a positive coefficient on the interaction of Shift and Context and a negative coefficient on the interaction of Opponent's Past Exaggeration and Context. Finally, the Decay Hypothesis predicts that these interactive effects become smaller with repetition of the game.

Once we control for Opponent's Past Exaggeration, a clear difference emerges between the Baseline and Context Conditions (see Figure 4 and Appendix Table A-2 for complete details). In the first round, the slope on Shift in the Context Condition exceeds that in the Baseline Condition ( $p=0.033$ ). And, as predicted, there are no significant differences between either intercept pair in the first round. ${ }^{18}$ Consistent with the Decay Hypothesis, this difference vanishes by the last round.

An alternative explanation for our findings is that context might make the strategic incentives clearer and enhances subjects' ability to learn to play the game. There are several pieces of evidence, however, that suggest against the context-enhanced learning interpretation. First, when we compare the number of correct answers in the pre-game instruction check across conditions, there are actually fewer correct answers in the Context Condition (6.6 per subject) rather than the Baseline Condition (6.9 per subject) but the difference is not statistically significant ( $p=0.31$, two-tailed). Second, we do not find any significant interactions between Context $\mathrm{x}$ Round and the other variables, which we would expect if context enhanced learning. Furthermore, when we reanalyze the data without the

${ }^{18}$ In addition, comparing the observed messages to the predicted best responses to past exaggeration of hypothetical agents who exhibit no aversion to lying $(\lambda=1)$ provides further evidence regarding the role of lying aversion in our analysis (see Appendix Table A-3). While the observed messages are strongly correlated with the predicted best responses, they are also consistently less extreme (exaggeration closer to 0 ), and this finding bolsters our confidence in the role of lying aversion. 

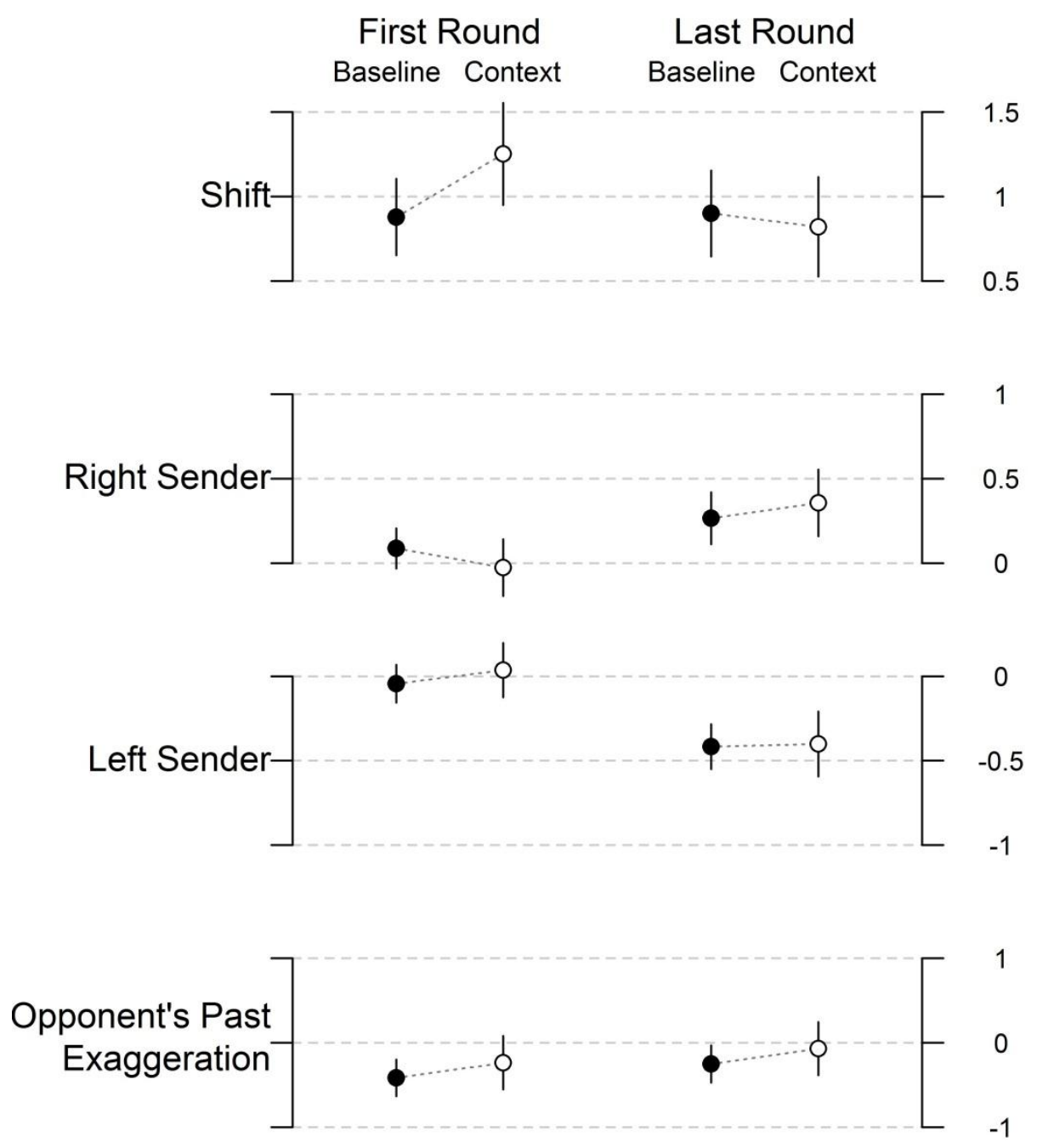

Figure 4: Context and Experience. Controlling for the effect of experience in repeated rounds of the game indicates that context effects decay Estimates are based on a multilevel regression of Message on Shift, Opponent's Past Exaggeration, Left Sender and Right Sender, and the interaction of each with Context and Round, with a control for Target. See model [3] from Appendix Table A-2 for details.

first five rounds to allow for players to gain initial experience, we do not find the context effect to be strongest in round 6 as the context-enhanced learning interpretation would suggest. ${ }^{19}$

19 See Appendix Table A-4 for details of the additional analysis. 
Some discrepancies between theory and evidence also emerge. In both conditions, the intercepts do start near zero in the first round, but by the last round they move far away from zero. Thus, messages become more polarized over time as senders learn to exaggerate more later in the game than earlier, but in a way that is unrelated to their payoffs or experiences. Because Receivers consistently choose actions close to the average message, increased polarization combined with the inherent randomness in Senders' biases implies that Receivers become worse off over time. ${ }^{20}$ Moreover, there are no significant differences between the coefficients on Opponent's Past Exaggeration in the two conditions. Thus, the predictions of the experiential best response framework fare better than do the equilibrium predictions, but anomalous phenomena remain.

\section{Conclusion}

In this paper, we first develop a formal model of communicative competition and lying aversion and then present evidence from an experiment based on that model. The primary challenge in testing models with pro-social preferences like lying aversion is that these preferences are unobservable and hence beyond the fine control of the experimenter. In our experiment, we attempted to influence lying aversion by manipulating the context in which subjects play the game. Specifically, in our Context Condition, senders are called "lobbyists" and read a short prompt that primes their uncertain incentives to lie, whereas in our Baseline Condition, all roles have abstract names and there is no prompt. We find that, after conditioning on subjects' experience in repeated play, there is clear evidence that

${ }^{20}$ See Appendix Table A-5 for details of a multi-level model of Receivers' actions as a function of average messages (with context and round interactions). 
senders in the Context Condition weight their own preferences more highly than in the Baseline Condition. This finding is especially interesting because the strategic setup of the game is identical in both conditions.

We can infer from this finding that subjects' behavior in communicative competition settings depends on lying aversion, which can be activated and accentuated. Moreover, we find that senders exaggerate their messages even more in later rounds of the game, regardless of context. This exaggeration emerges even after controlling for payoffs and experiences. This finding is not predicted by analysis of the formal model. Given that subjects do seem averse to lying, it is intriguing that they also seem to lie more later in the game. One intriguing possibility is the emergence of exaggeration via message inflation. In early rounds, subjects might choose messages that reflect their payoffs and their expectations of their opponents' messages, and then add in an extra dash of exaggeration. If that is true, in later rounds, senders might take initial dashes of exaggeration into account, and then add their own. Thus, exaggeration might accrue round after round, and thereby culminate in the evidence we present. Future research should focus on more fully understanding and exploring the reasons for such inflation in the degree of exaggeration.

The clear message of this study is that lying aversion, which is the theoretical cause of overcommunication in single-sender games, may have very different consequences in multiple-sender environments than it does in single-sender environments. In a single-sender environment, lying aversion leads the lone sender to reveal more information than he should in equilibrium. In a multiple-sender environment, there is no such clear change in the amount of information conveyed to the receiver. Both theoretically and empirically, the best the receiver can do in such an environment is to observe the two 
messages she receives, and average them together. Regardless of the degree of lying aversion, there is no clear change in the information conveyed to the receiver.

From the perspective of the sender, lying aversion and competition constitute incentives that point in different directions. Without engaging in repeated play, the lying aversion incentive tends to win out, and senders overcommunicate. However, after many repetitions, the incentive to tell the truth is crowded out by the competitive incentive to exaggerate. Indeed, by the final round it appears that senders have moved from a strategy of overcommunication to a strategy of persistent exaggeration.

Substantively, this study provides us with some of the first evidence of behavior in environments with communicative competition, and hence insight into many important political environments. Congressional committees gather information by calling numerous witnesses to testify, many of whome represent competing viewpoints and interests. Regulators rely on data from industries as well as career bureaucrats, whose goals often differ from those of the political principals. Everyday political discourse transmitted through the media typically features relatively well informed elites making claims about public policy to relatively poorly informed members of the public on a wide range of issues. Consider, for example, conflicting advice the public receives about the economic consequences of raising or lowering marginal tax rates, the imposition of domestic spending cuts, or health insurance mandates. If the elites are even mildly lying averse, our formal model provides some insight into their message strategies, which principally concern the extent to which they should exaggerate. In the experimental findings, exaggeration tended to increase over time, which matches the familiar narrative of the increasingly bitter tone of a dysfunctional and polarized contemporary politics. 


\section{References}

Blume, Andreas, Douglas V. DeJong, Yong-Gwan Kim, and Geoffrey B. Sprinkle. 1998.

"Experimental Evidence on the Evolution of Meaning of Messages in

Sender-Receiver Games." American Economic Review 88: 1323-1340.

Blume, Andreas, Douglas V. DeJong, Yong-Gwan Kim, and Geoffrey B. Sprinkle. 2001.

"Evolution of Communication with Partial Common Interest." Games and Economic Behavior 37: 79-120.

Border, Kim C. 1985. Fixed Point Theorems with Applications to Economics and Game Theory Cambridge: Cambridge University Press.

Boudreau, Cheryl, and Mathew D. McCubbins. 2008. "Nothing but the Truth? Experiments on Adversarial Competition, Expert Testimony, and Decision Making." Journal of Empirical Legal Studies 5(December): 751-789.

Burnham, Terence, Kevin McCabe, and Vernon L. Smith. 2000. "Friend-or-foe Intentionality Priming in an Extensive Form Trust Game." Journal of Economic Behavior \& Organization 43(1): 57-73.

Cai, Hongbin, and Joseph Tao-Yi Wang. 2006. “Overcommuniation in Strategic Information Transmission Games." Games and Economic Behavior 56: 7-36.

Crawford, Vincent, and Joel Sobel. 1982. "Strategic Information Transmission." Econometrica 50: 1431-1451.

Crawford, Vincent P. 1998. "A Survey of Experiments on Communication via Cheap Talk." Journal of Economic Theory 78: 286-298.

Dickhaut, John W., Kevin A. McCabe, and Arijit Mukherji. 1995. "An Experimental Study of Strategic Information Transmission." Economic Theory 6: 389-403. 
Dickson, Eric S., Catherine Hafer, and Dimitri Landa. 2008. “Cognition and Strategy: A Deliberation Experiment." The Journal of Politics 70(04): 974-989.

Dufwenberg, Martin, Simon Gachter, and Heike Hennig-Schmidt. 2011. "The Framing of Games and the Psychology of Play." Games and Economic Behavior 73: 459-78.

Fischbacher, Urs. 2007. "z-Tree: Zurich toolbox for ready-made economic experiments." Experimental Economics 10: 171-178.

Gilligan, Thomas W., and Keith Krehbiel. 1987. “Collective Decisionmaking and Standing Committees: An Informational Rationale for Restrictive Amendment Procedures." Journal of Law, Economics, and Organization 3: 287-335.

Gneezy, Uri. 2005. “Deception: The Role of Consequences.” American Economic Review 95: 384-394.

Hurkens, Sjaak, and Navin Kartik. 2009. "Would I Lie to You? On Social Preferences and Lying Aversion." Experimental Economics 12: 180-192.

Levitt, Steven D., and John A. List. 2007. “What Do Laboratory Experiments Measuring Social Preferences Reveal About the Real World?" Journal of Economic Perspectives 21(2): 153-174.

Lupia, Arthur, and Mathew D. McCubbins. 1998. The Democratic Dilemma: Can Citizens Learn What They Need to Know? Cambridge: Cambridge University Press.

Minozzi, William. 2011. “A Jamming Theory of Politics." Journal of Politics 73(2): 301-315.

Minozzi, William, and Jonathan Woon. n.d. “Competition, Preference Uncertainty, and Jamming: A Strategic Communication Experiment." Working paper.

Rode, J. 2010. "Truth and trust in communication: Experiments on the effect of a competitive context." Games and Economic Behavior 68(1): 325-338. 
Ross, William T., Jr., and Diana C. Robertson. 2000. "Lying: The Impact of Decision Context." Business Ethics Quarterly 10(2): 409-440.

Sánchez-Pagés, Santiago, and Marc Vorsatz. 2007. "An Experimental Study of Truth-Telling in a Sender-Receiver Game." Games and Economic Behavior 61(1): 86-112.

Sánchez-Pagés, Santiago, and Marc Vorsatz. 2009. “Enjoy the Silence: An Experiment on Truth-Telling." Experimental Economics 12(1): 220-241. 


\section{Appendix}

\section{Statistical Tables}

Table A-1: Summary Statistics for Experimental Sessions

\begin{tabular}{|c|c|c|c|c|c|c|}
\hline & \multirow[b]{2}{*}{1} & \multicolumn{5}{|c|}{ Session } \\
\hline & & 2 & 3 & 4 & 5 & 6 \\
\hline Condition & Baseline & Baseline & Baseline & Baseline & Context & Context \\
\hline Subjects & 18 & 15 & 18 & 18 & 15 & 15 \\
\hline Rounds & 32 & 32 & 24 & 24 & 32 & 32 \\
\hline Target $T$ & $\begin{array}{c}0.01 \\
(0.58)\end{array}$ & $\begin{array}{c}0.00 \\
(0.58)\end{array}$ & $\begin{array}{c}0.04 \\
(0.59)\end{array}$ & $\begin{array}{c}0.05 \\
(0.63)\end{array}$ & $\begin{array}{l}-0.00 \\
(0.58)\end{array}$ & $\begin{array}{c}0.01 \\
(0.59)\end{array}$ \\
\hline Shift $S_{L}$ & $\begin{array}{l}-0.26 \\
(0.15)\end{array}$ & $\begin{array}{l}-0.25 \\
(0.15)\end{array}$ & $\begin{array}{l}-0.25 \\
(0.15)\end{array}$ & $\begin{array}{l}-0.25 \\
(0.14)\end{array}$ & $\begin{array}{l}-0.25 \\
(0.15)\end{array}$ & $\begin{array}{l}-0.24 \\
(0.14)\end{array}$ \\
\hline Shift $S_{R}$ & $\begin{array}{c}0.25 \\
(0.15)\end{array}$ & $\begin{array}{c}0.26 \\
(0.15)\end{array}$ & $\begin{array}{c}0.24 \\
(0.14)\end{array}$ & $\begin{array}{c}0.25 \\
(0.15)\end{array}$ & $\begin{array}{c}0.25 \\
(0.15)\end{array}$ & $\begin{array}{l}0.25 \\
(0.15)\end{array}$ \\
\hline Message $m_{L}$ & $\begin{array}{l}-0.59 \\
(0.59)\end{array}$ & $\begin{array}{l}-0.73 \\
(0.60)\end{array}$ & $\begin{array}{l}-0.57 \\
(0.62)\end{array}$ & $\begin{array}{l}-0.60 \\
(0.64)\end{array}$ & $\begin{array}{l}-0.47 \\
(0.59)\end{array}$ & $\begin{array}{l}-0.51 \\
(0.67)\end{array}$ \\
\hline Message $m_{R}$ & $\begin{array}{c}0.41 \\
(0.67)\end{array}$ & $\begin{array}{c}0.78 \\
(0.66)\end{array}$ & $\begin{array}{c}0.63 \\
(0.63)\end{array}$ & $\begin{array}{c}0.57 \\
(0.63)\end{array}$ & $\begin{array}{c}0.54 \\
(0.61)\end{array}$ & $\begin{array}{c}0.50 \\
(0.60)\end{array}$ \\
\hline Action $c$ & $\begin{array}{l}-0.08 \\
(0.58)\end{array}$ & $\begin{array}{c}0.03 \\
(0.58)\end{array}$ & $\begin{array}{c}0.02 \\
(0.59)\end{array}$ & $\begin{array}{c}0.05 \\
(0.63)\end{array}$ & $\begin{array}{c}0.02 \\
(0.50)\end{array}$ & $\begin{array}{c}0.04 \\
(0.52)\end{array}$ \\
\hline $\begin{array}{l}\text { Opponent's Past } \\
\text { Exaggeration } \bar{\xi}_{R}\end{array}$ & $\begin{array}{c}0.39 \\
(0.13)\end{array}$ & $\begin{array}{c}0.58 \\
(0.19)\end{array}$ & $\begin{array}{c}0.45 \\
(0.11)\end{array}$ & $\begin{array}{c}0.43 \\
(0.10)\end{array}$ & $\begin{array}{c}0.45 \\
(0.09)\end{array}$ & $\begin{array}{c}0.40 \\
(0.09)\end{array}$ \\
\hline $\begin{array}{l}\text { Opponent's Past } \\
\text { Exaggeration } \bar{\xi}_{L}\end{array}$ & $\begin{array}{l}-0.55 \\
(0.14)\end{array}$ & $\begin{array}{l}-0.53 \\
(0.20)\end{array}$ & $\begin{array}{l}-0.43 \\
(0.12)\end{array}$ & $\begin{array}{l}-0.42 \\
(0.17)\end{array}$ & $\begin{array}{l}-0.40 \\
(0.09)\end{array}$ & $\begin{array}{l}-0.41 \\
(0.13)\end{array}$ \\
\hline
\end{tabular}

All parameters are have been rescaled by $1 / 100$ except Round which was rescaled by $1 / 32$. 
Table A-2: Context and Communicative Competition

\begin{tabular}{|c|c|c|c|}
\hline $\mathrm{DV}=$ Message & [1] & [2] & [3] \\
\hline Target & $\begin{array}{c}0.89 \\
(0.01)\end{array}$ & $\begin{array}{c}0.89 \\
(0.01)\end{array}$ & $\begin{array}{r}0.90 \\
(0.01)\end{array}$ \\
\hline Shift & $\begin{array}{c}0.86 \\
(0.07)\end{array}$ & $\begin{array}{c}0.88 \\
(0.10)\end{array}$ & $\begin{array}{c}0.88 \\
(0.11)\end{array}$ \\
\hline Opponent's Past Exaggeration & & & $\begin{array}{l}-0.42 \\
(0.11)\end{array}$ \\
\hline Left Sender & $\begin{array}{l}-0.41 \\
(0.04)\end{array}$ & $\begin{array}{l}-0.19 \\
(0.05)\end{array}$ & $\begin{array}{l}-0.04 \\
(0.06)\end{array}$ \\
\hline Right Sender & $\begin{array}{c}0.39 \\
(0.04)\end{array}$ & $\begin{array}{c}0.22 \\
(0.04)\end{array}$ & $\begin{array}{c}0.09 \\
(0.06)\end{array}$ \\
\hline Context $\times$ Shift & $\begin{array}{c}0.16 \\
(0.12)\end{array}$ & $\begin{array}{c}0.30 \\
(0.18)\end{array}$ & $\begin{array}{c}0.37 \\
(0.18)\end{array}$ \\
\hline Context $\times$ Opp.'s Past Exag. & & & $\begin{array}{c}0.18 \\
(0.16)\end{array}$ \\
\hline Context $\times$ Left & $\begin{array}{c}0.16 \\
(0.06)\end{array}$ & $\begin{array}{c}0.15 \\
(0.08)\end{array}$ & $\begin{array}{c}0.08 \\
(0.09)\end{array}$ \\
\hline Context $\times$ Right & $\begin{array}{l}-0.15 \\
(0.07)\end{array}$ & $\begin{array}{l}-0.15 \\
(0.08)\end{array}$ & $\begin{array}{l}-0.11 \\
(0.10)\end{array}$ \\
\hline Round $\times$ Shift & & $\begin{array}{l}-0.05 \\
(0.18)\end{array}$ & $\begin{array}{c}0.02 \\
(0.20)\end{array}$ \\
\hline Round $\times$ Opp.'s Past Exag. & & & $\begin{array}{r}0.16 \\
(0.17)\end{array}$ \\
\hline Round $\times$ Left & & $\begin{array}{l}-0.46 \\
(0.06)\end{array}$ & $\begin{array}{l}-0.37 \\
(0.09)\end{array}$ \\
\hline Round $\times$ Right & & $\begin{array}{c}0.35 \\
(0.06)\end{array}$ & $\begin{array}{c}0.18 \\
(0.10)\end{array}$ \\
\hline Context $\times$ Round $\times$ Shift & & $\begin{array}{l}-0.22 \\
(0.27)\end{array}$ & $\begin{array}{l}-0.45 \\
(0.27)\end{array}$ \\
\hline Context $\times$ Round $\times$ Opp.'s Past Exag. & & & $\begin{array}{r}0.00 \\
(0.23)\end{array}$ \\
\hline Context $\times$ Round $\times$ Left & & $\begin{array}{c}0.04 \\
(0.09)\end{array}$ & $\begin{array}{l}-0.07 \\
(0.14)\end{array}$ \\
\hline Context $\times$ Round $\times$ Right & & $\begin{array}{l}-0.04 \\
(0.09)\end{array}$ & $\begin{array}{c}0.20 \\
(0.15)\end{array}$ \\
\hline Subject Error Term SD & & & \\
\hline $\begin{array}{l}\text { Shift } \\
\text { Opp.'s Past Exag. }\end{array}$ & 0.34 & 0.35 & $\begin{array}{l}0.35 \\
0.31\end{array}$ \\
\hline Left Sender & 0.15 & 0.15 & 0.13 \\
\hline Right Sender & 0.15 & 0.15 & 0.19 \\
\hline Round Error Term SD & & & \\
\hline Shift & 0.10 & 0.08 & 0.15 \\
\hline Opp.'s Past Exag. & & & 0.20 \\
\hline Left Sender & 0.14 & 0.05 & 0.09 \\
\hline Right Sender & 0.11 & 0.04 & 0.07 \\
\hline Residual & 0.22 & 0.22 & 0.21 \\
\hline$n$ Observations & 1920 & 1920 & 1854 \\
\hline$n$ Subjects & 66 & 66 & 66 \\
\hline$n$ Rounds & 32 & 32 & 31 \\
\hline
\end{tabular}


Table A-3: Messages versus Non-Lying Averse Best Responses to Opponent's Past Exaggeration

\begin{tabular}{|c|c|}
\hline \multicolumn{2}{|l|}{$\mathrm{DV}=$ Message } \\
\hline Predicted Best Response & 0.91 \\
\hline Left Sender & $\begin{array}{c}(0.02) \\
0.29 \\
(0.04)\end{array}$ \\
\hline Right Sender & $\begin{array}{l}-0.28 \\
(0.05)\end{array}$ \\
\hline Context $\times$ Pred. Best Resp. & $\begin{array}{l}-0.01 \\
(0.04)\end{array}$ \\
\hline Context $\times$ Left Sender & $\begin{array}{c}0.07 \\
(0.07)\end{array}$ \\
\hline Context $\times$ Right Sender & $\begin{array}{l}-0.03 \\
(0.08)\end{array}$ \\
\hline Round $\times$ Pred. Best Resp. & $\begin{array}{l}-0.17 \\
(0.04)\end{array}$ \\
\hline Round $\times$ Left Sender & $\begin{array}{l}-0.22 \\
(0.06)\end{array}$ \\
\hline Round $\times$ Right Sender & $\begin{array}{c}0.10 \\
(0.06)\end{array}$ \\
\hline Context $\times$ Round $\times$ Pred. Best Resp. & $\begin{array}{c}0.13 \\
(0.06)\end{array}$ \\
\hline Context $\times$ Round $\times$ Left Sender & $\begin{array}{c}0.16 \\
(0.08)\end{array}$ \\
\hline Context $\times$ Round $\times$ Right Sender & $\begin{array}{l}-0.12 \\
(0.09)\end{array}$ \\
\hline \multicolumn{2}{|l|}{ Subject Error Term $S D$} \\
\hline Shift & 0.39 \\
\hline Left Sender & 0.13 \\
\hline Right Sender & 0.15 \\
\hline \multicolumn{2}{|l|}{ Round Error Term SD } \\
\hline Shift & 0.69 \\
\hline Left Sender & 0.15 \\
\hline Right Sender & 0.16 \\
\hline Residual & 0.24 \\
\hline$n$ Observations & 1854 \\
\hline$n$ Subjects & 66 \\
\hline$n$ Rounds & 31 \\
\hline
\end{tabular}


Table A-4: Estimates Dropping Rounds 1-5

\begin{tabular}{|c|c|c|c|}
\hline DV $=$ Message & [1] & [2] & [3] \\
\hline Target & $\begin{array}{c}0.89 \\
(0.01)\end{array}$ & $\begin{array}{c}0.89 \\
(0.01)\end{array}$ & $\begin{array}{c}0.90 \\
(0.01)\end{array}$ \\
\hline Shift & $\begin{array}{c}0.86 \\
(0.08)\end{array}$ & $\begin{array}{c}0.98 \\
(0.17)\end{array}$ & $\begin{array}{c}0.94 \\
(0.16)\end{array}$ \\
\hline Opponent's Past Exaggeration & & & $\begin{array}{l}-0.45 \\
(0.14)\end{array}$ \\
\hline Left Sender & $\begin{array}{l}-0.46 \\
(0.04)\end{array}$ & $\begin{array}{l}-0.26 \\
(0.06)\end{array}$ & $\begin{array}{c}-0.07 \\
(0.09)\end{array}$ \\
\hline Right Sender & $\begin{array}{c}0.42 \\
(0.05)\end{array}$ & $\begin{array}{c}0.24 \\
(0.07)\end{array}$ & $\begin{array}{c}0.04 \\
(0.09)\end{array}$ \\
\hline Context $\times$ Shift & $\begin{array}{c}0.13 \\
(0.12)\end{array}$ & $\begin{array}{c}0.26 \\
(0.23)\end{array}$ & $\begin{array}{c}0.32 \\
(0.23)\end{array}$ \\
\hline Context $\times$ Opp.'s Past Exag. & & & $\begin{array}{c}0.27 \\
(0.21)\end{array}$ \\
\hline Context $\times$ Left & $\begin{array}{c}0.17 \\
(0.07)\end{array}$ & $\begin{array}{c}0.14 \\
(0.09)\end{array}$ & $\begin{array}{c}0.01 \\
(0.12)\end{array}$ \\
\hline Context $\times$ Right & $\begin{array}{l}-0.14 \\
(0.08)\end{array}$ & $\begin{array}{l}-0.13 \\
(0.10)\end{array}$ & $\begin{array}{l}-0.01 \\
(0.13)\end{array}$ \\
\hline Round $\times$ Shift & & $\begin{array}{l}-0.25 \\
(0.28)\end{array}$ & $\begin{array}{l}-0.10 \\
(0.27)\end{array}$ \\
\hline Round $\times$ Opp.'s Past Exag. & & & $\begin{array}{c}0.23 \\
(0.23)\end{array}$ \\
\hline Round $\times$ Left & & $\begin{array}{l}-0.38 \\
(0.08)\end{array}$ & $\begin{array}{l}-0.36 \\
(0.13)\end{array}$ \\
\hline Round $\times$ Right & & $\begin{array}{c}0.33 \\
(0.10)\end{array}$ & $\begin{array}{c}0.27 \\
(0.14)\end{array}$ \\
\hline Context $\times$ Round $\times$ Shift & & $\begin{array}{l}-0.16 \\
(0.36)\end{array}$ & $\begin{array}{l}-0.34 \\
(0.34)\end{array}$ \\
\hline Context $\times$ Round $\times$ Opp.'s Past Exag. & & & $\begin{array}{l}-0.16 \\
(0.31)\end{array}$ \\
\hline Context $\times$ Round $\times$ Left & & $\begin{array}{c}0.08 \\
(0.11)\end{array}$ & $\begin{array}{c}0.09 \\
(0.19)\end{array}$ \\
\hline Context $\times$ Round $\times$ Right & & $\begin{array}{l}-0.05 \\
(0.11)\end{array}$ & $\begin{array}{c}0.01 \\
(0.19)\end{array}$ \\
\hline Subject Error Term SD & & & \\
\hline $\begin{array}{l}\text { Shift } \\
\text { Opp.'s Past Exag. }\end{array}$ & 0.33 & 0.34 & $\begin{array}{l}0.35 \\
0.30\end{array}$ \\
\hline Left Sender & 0.16 & 0.17 & 0.15 \\
\hline Right Sender & 0.18 & 0.18 & 0.21 \\
\hline Round Error Term SD & & & \\
\hline Shift & 0.16 & 0.21 & 0.20 \\
\hline Opp.'s Past Exag. & & & 0.22 \\
\hline Left Sender & 0.09 & 0.03 & 0.10 \\
\hline Right Sender & 0.10 & 0.08 & 0.10 \\
\hline Residual & 0.22 & 0.22 & 0.20 \\
\hline$n$ Observations & 1590 & 1590 & 1590 \\
\hline$n$ Subjects & 66 & 66 & 66 \\
\hline$n$ Rounds & 27 & 27 & 27 \\
\hline
\end{tabular}


Table A-5: Actions versus Average Messages

\begin{tabular}{lc}
\hline $\mathrm{DV}=$ Action - Average Message & \\
\hline Context & -0.01 \\
& $(0.03)$ \\
Round & -0.01 \\
& $(0.03)$ \\
Context $\times$ Round & 0.04 \\
& $(0.04)$ \\
Intercept & 0.01 \\
& $(0.02)$ \\
& \\
Subject Error Term SD & 0.03 \\
Round Error Term SD & 0.04 \\
Residual & 0.17 \\
$n$ Observations & 960 \\
$n$ Subjects & 33 \\
$n$ Rounds & 32 \\
\hline
\end{tabular}




\section{Formal Model}

Two senders $I \in\{L, R\}$ and one receiver play a strategic information transmission game. The state of the world (or target) $T \in \mathbf{T}$ has uniform distribution. ${ }^{21}$ Each sender has a bias (or shift) $S_{I} \in \mathbf{S}_{I}$ which has atomless distribution $G_{I}$ with full support, where $S_{L}=[-\bar{S}, 0]$ and $S_{R}=[0, \bar{S}]$ for $\bar{S} \leq \frac{1}{4}$. Each sender also has a lying aversion parameter $\lambda_{I} \in[0,1]$, which has atomless distribution $F_{I}(\cdot, \theta)$. Let $\theta \in \Theta$ be commonly known, and assume that the distributions $F_{I}$ are ordered by $\theta$ with respect to first order stochastic dominance. All random variables are assumed to be independently drawn.

The timing of the game is as follows. First, Nature draws $\left(T, S_{L}, S_{R}, \lambda_{L}, \lambda_{R}\right)$ and reveals $\left(T, S_{I}, \lambda_{I}\right)$ to sender $I$. Then each sender chooses a message $m_{I} \in \mathrm{R}$ (the set of real numbers) to send to the receiver. Finally, the receiver observes $\left(m_{L}, m_{R}\right)$ and chooses $c \in \mathrm{R}$. Preferences are quasilinear in spatial payoffs and lying aversion. Sender I 's utility function is $v\left(\left|c-\left(T+S_{I}\right)\right|\right)+\kappa\left(\left|m_{I}-T\right| ; \lambda_{I}\right)$, and the receiver's utility function is $v(|c-T|)$, where $v(\cdot)$ is a decreasing, concave function. Assume that the lying aversion function $\kappa\left(x ; \lambda_{I}\right)$ is strictly decreasing, concave, and continuous in $x$, and strictly increasing and continuous in $\lambda_{I}$. Assume $\kappa_{I}(x ; 0)=-\delta(x)$, the Dirac delta function, and $\kappa_{I}(x ; 1)=0 .{ }^{22}$ All elements of the game are common knowledge unless otherwise specified.

Message strategies are maps $m_{I}: \mathbf{T} \times \mathbf{S}_{\mathbf{I}} \times[0,1] \rightarrow \mathrm{R}$ and the choice strategy of the

${ }^{21}$ The substative results would hold for any atomless distribution with full support.

${ }^{22}$ Therefore $\kappa$ is actually not strictly decreasing at $\lambda \in\{0,1\}$, but this will not affect the results below. 
receiver is $c: \mathrm{R} \times \mathrm{R} \rightarrow \mathrm{R}$. Define by $g=\left(G_{L}, G_{R}, F_{L}, F_{R}, \bar{S}, v, \kappa, \theta\right)$ a game in this class of SIT models. The receiver's beliefs are given by the probability density $h\left(\cdot \mid m_{L}, m_{R}\right)$ on $T$. We study perfect Bayesian equilibria.

Proposition 1. An equilibrium exists for any $g$.

Proof. Given her posterior beliefs about $T$, the receiver chooses $c\left(m_{L}, m_{R}\right)=E\left[T \mid m_{L}, m_{R}\right]$ because her preferences are a symmetric loss function from $T$. For sender $L$, any message $m_{L}>T$ that would induce the receiver to choose $c \geq T$ is strictly dominated by $m_{L}=T$ for almost every $\lambda_{L}$. Similarly, any $m_{R}<T$ is strictly dominated for sender $R$. Thus, in equilibrium, it must be that $m_{L} \leq T \leq m_{R}$.

The receiver's posterior beliefs about $T$ given $m_{L} \leq m_{R}$ must satisfy

$$
P\left(T \mid m_{L}, m_{R}\right)=\frac{P\left(m_{L}, m_{R} \mid T\right)}{\int_{m_{L}}^{m_{R}} P\left(m_{L}, m_{R} \mid \tilde{T}\right) d \tilde{T}},
$$

where $P\left(m_{L}, m_{R} \mid T\right)$ is the conditional probability of observing the message pair $\left(m_{L}, m_{R}\right)$ given $T$. Suppose senders use message strategies that are differentiable in each of their arguments. Given those message strategies, the target $T$ and message $m_{I}$ identify a contour $C\left(T, m_{I}\right) \subset \mathbf{S}_{I} \times[0,1]$ such that for any $\left(S_{I}, \lambda_{I}\right) \in C\left(T, m_{I}\right)$, sender $I$ would have sent message $m_{I}$ if the target were $T$. Then $P\left(m_{I} \mid T\right)=\int_{C\left(T, m_{I}\right)} d G_{I} d F_{I}$, and $P\left(m_{L}, m_{R} \mid T\right)=P\left(m_{R} \mid T\right) P\left(m_{L} \mid T\right)$. Denote on-the-path beliefs by the density $h\left(T \mid m_{L}, m_{R}\right)=P\left(T \mid m_{L}, m_{R}\right)$. Because message strategies are differentiable in each of their 
arguments, $h\left(T \mid m_{L}, m_{R}\right)$ is differentiable in $m_{L}$ and $m_{R}$.

Using these beliefs, the receiver's strategy is to choose

$c\left(m_{L}, m_{R}\right)=\int_{m_{L}}^{m_{R}} T h\left(T \mid m_{L}, m_{R}\right) d T$. Suppose each sender expects the other to use a

differentiable message strategy. Consider the problem faced by sender $I$. His best

response solves the problem

$$
\max _{m_{I}} E_{I}\left[v\left(\left|\tilde{c}-\left(T+S_{I}\right)\right|\right)\right]+\kappa\left(\left|m_{I}-T\right| ; \lambda_{I}\right),
$$

where $E_{I}[\cdot]$ represents expectation from sender $I$ 's perspective, i.e. with respect to the prior distributions of the shift and lying aversion of the other sender. Given $\tilde{c}(\cdot)$, the first order conditions for the two senders are

$$
\begin{aligned}
& \kappa^{\prime}\left(T-m_{L} ; \lambda_{L}\right)=E_{L}\left[v^{\prime}\left(\tilde{c}-T-S_{L}\right) \frac{\partial \tilde{c}}{\partial m_{L}}\right] \text { and } \\
& \kappa^{\prime}\left(m_{R}-T ; \lambda_{R}\right)=E_{R}\left[v^{\prime}\left(T+S_{R}-\tilde{c}\right) \frac{\partial \tilde{c}}{\partial m_{R}}\right] .
\end{aligned}
$$

Let $\xi\left(\cdot ; \lambda_{I}\right)$ be the inverse function of $\kappa^{\prime}\left(\cdot ; \lambda_{I}\right)$. Such a function exists because $\kappa$ is strictly decreasing and concave in its interior. Moreover, these assumptions imply that $\xi(\cdot)$ takes negative arguments, has nonnegative values, and is strictly decreasing.

$$
\begin{aligned}
& \tilde{m}_{L}=T-\xi\left(E_{L}\left[v^{\prime}\left(\tilde{c}-T-S_{L}\right) \frac{\partial \tilde{c}}{\partial m_{L}}\right] ; \lambda_{L}\right) \text { and } \\
& \tilde{m}_{R}=T+\xi\left(E_{R}\left[v^{\prime}\left(T+S_{R}-\tilde{c}\right) \frac{\partial \tilde{c}}{\partial m_{R}}\right] ; \lambda_{R}\right)
\end{aligned}
$$

Each of these equations implicitly identifies a best response function. An appropriate fixed point theorem, e.g. the Fan-Browder theorem (Border 1985), provides for the existence of 
message strategies and on-the-path beliefs that satisfy these criteria.

The last step is to specify off-the-path beliefs for the receiver if ever $m_{L}>m_{R}$. In that case, specify $h\left(T \mid m_{L}, m_{R}\right)=\frac{1}{m_{L}-m_{R}}$, the uniform distribution. Such messages remain strictly dominated, and therefore, these off-the-path beliefs support an equilibrium. Consider now the special case in the text. In this case, we have the following equilibrium.

Proposition 2. Suppose $G_{L}$ and $G_{R}$ are uniform distributions, $F_{L}=F_{R}$ with

$$
\begin{gathered}
\mu=E\left[\lambda_{L}\right]=E\left[\lambda_{R}\right], v(x)=-x^{2} \text {, and } \kappa\left(x ; \lambda_{I}\right)=-\frac{1-\lambda_{I}}{4 \lambda_{I}} x^{2} . \text { Let } S=E\left|S_{L}\right|=E\left|S_{R}\right| \text {, and } \\
A(\theta)=\frac{\mu}{1-\mu} . \text { The strategies } \\
m_{L}^{*}=T+2 \lambda_{L} S_{L}-2 \lambda_{L} S A(\theta), \\
m_{R}^{*}=T+2 \lambda_{R} S_{R}+2 \lambda_{R} S A(\theta), \text { and } \\
c^{*}=\frac{1}{2}\left(m_{L}+m_{R}\right),
\end{gathered}
$$

with beliefs given by $h\left(T \mid m_{L}, m_{R}\right)$ symmetric about $c^{*}$ constitute an equilibrium.

Proof. First note that in this case, $v^{\prime}(x)=-2 x, \kappa^{\prime}\left(x ; \lambda_{I}\right)=-\frac{1-\lambda_{I}}{2 \lambda_{I}} x$, and $\frac{\partial \tilde{c}}{\partial m_{I}}=\frac{1}{2}$ for $i \in\{L, R\}$. The first order conditions from Proposition 1 are

$$
-\frac{1-\lambda_{R}}{2 \lambda_{R}}\left(m_{R}-T\right)=T+S_{R}-E_{R}[\tilde{c}] \text { and }
$$




$$
-\frac{1-\lambda_{L}}{2 \lambda_{L}}\left(T-m_{L}\right)=E_{L}[\tilde{c}]-T-S_{L} .
$$

Substituting in $c^{*}=\frac{1}{2}\left(m_{L}+m_{R}\right)$, multiplying both sides by 2 , and rearranging yields best response message strategies

$$
\begin{aligned}
& m_{R}=\left(1+\lambda_{R}\right) T+2 \lambda_{R} S_{R}-\lambda_{R} E_{R}\left[m_{L}\right] \text { and } \\
& m_{L}=\left(1+\lambda_{L}\right) T+2 \lambda_{L} S_{L}-\lambda_{L} E_{L}\left[m_{R}\right] .
\end{aligned}
$$

Now take conditional expectations and solve the system to get

$$
\begin{aligned}
& E_{L}\left[m_{R}\right]=T+2 S A(\theta) \text { and } \\
& E_{R}\left[m_{L}\right]=T-2 S A(\theta) .
\end{aligned}
$$

Finally, substitute back into the best response message strategies to get the message strategies in the statement of the proposition.

Given these strategies, consider the receiver's posterior (on-the-path) beliefs. For any pair of messages $\left(m_{L}, m_{R}\right)$, the set of values of $T$ is a subset of $\left[m_{L}, m_{R}\right]$. First, the furthest $T$ could be from $m_{L}$ in equilibrium is when $\lambda_{L}=1$ and $S_{L}=-\bar{S}$, in which case $T=m_{L}+\bar{S}+S A(\theta)$. Similarly, the furthest $T$ could be from $m_{R}$ in equilibrium is when $\lambda_{R}=1$ and $S_{R}=\bar{S}$, in which case $T=m_{R}-\bar{S}-S A(\theta)$. Thus, the support of $h\left(\cdot \mid m_{L}, m_{R}\right)$ is $\left[m_{L}, m_{R}\right] \cap\left[m_{R}-\bar{S}-S A(\theta), m_{L}+\bar{S}+S A(\theta)\right]$. The symmetry of the shift and lying aversion distributions ensures the symmetry of the posterior density, meaning that the posterior expected value of $T$ is $c^{*}$.

\section{Experiential Best Response, Lying Aversion, and Communicative Competition}


Suppose (1) each sender $I$ believes that the receiver uses the strategy $c^{*}=1 / 2\left(m_{L}+m_{R}\right)$, and (2) each $I$ believes his opponent (notated $-I$ ) will send the message $E_{I}\left[m_{-I}\right]=T+\bar{\xi}_{-I}$.

Proposition 3. Suppose $G_{L}$ and $G_{R}$ are uniform distributions, $F_{L}=F_{R}$ with $\mu=E\left[\lambda_{L}\right]=E\left[\lambda_{R}\right], v(x)=-x^{2}$, and $\kappa\left(x ; \lambda_{I}\right)=-\frac{1-\lambda_{I}}{4 \lambda_{I}} x^{2}$. Let $S=E\left|S_{L}\right|=E\left|S_{R}\right|$, and $A(\theta)=\frac{\mu}{1-\mu}$. Further assume (1) and (2). The best response message strategies are

$$
m_{I}^{B R}=T+2 \lambda_{I} S_{I}-\lambda_{I} \bar{\xi}_{-I}
$$

for sender $i \in\{L, R\}$.

Proof. Sender I's best response solves the problem

$$
\max _{m_{I}}-\left(\frac{1}{2}\left(m_{I}+T+\bar{\xi}_{-I}\right)-\left(T+S_{I}\right)\right)^{2}-\frac{1-\lambda_{I}}{4 \lambda_{I}}\left(m_{I}-T\right)^{2},
$$

which has the first order condition $m_{I}^{B R}=T+2 \lambda_{I} S_{I}-\lambda_{I} \bar{\xi}_{-I}$.

\section{Experimental Instructions}

Instructions for both the Baseline condition and the Context condition appear below. Words in italics appeared only in the Baseline condition, and words in square brackets appeared only in the Context condition. 


\section{General Information [about the Lobbying Experiment]}

[Senators and representatives vote on many different pieces of legislation covering many different facets of domestic and foreign policy. But they are not experts on everything. Some legislators learn about the details of these issues by talking to lobbyists, who can represent businesses, citizen groups, other countries, or many other interests. Legislators, however, do not always know whether it is in the best interests of lobbyists to tell the truth.]

This is an experiment in communication. The University of Pittsburgh has provided funds for this research. If you follow the instructions closely and make appropriate decisions, you may make a considerable amount of money. In addition to the $\$ 7$ participation payment, these earnings will be paid to you, in cash, at the end of the experiment.

During the experiment, all earnings will be denominated in points, which will be converted to cash at the rate of $\$ 1$ per 150 points. The exact amount you receive will be determined during the experiment and will depend on your decisions and the decisions of others. You will be paid your earnings privately, meaning that no other participant will find out how much you earn. Also, each participant has a printed copy of these instructions. You may refer to your printed instructions at any time during the experiment.

If you have any questions during the experiment, please raise your hand and wait for an experimenter to come to you. Please do not talk, exclaim, or try to communicate with other participants during the experiment. Also, please ensure 
that your cell phones are turned off and put away for the duration of the experiment. Participants intentionally violating the rules will be asked to leave the experiment and may not be paid.

\section{Roles, Rounds, and Matching}

Each participant will be assigned to one of three roles: [Lobbyist] A, [Lobbyist] B, or $C$ [the Legislator]. Your role will be assigned before the first round and will remain fixed throughout the experiment.

In this experiment you will make decisions in a series of rounds, and there are a total of 32 rounds. Each round is a separate decision task. Before every round, you will be randomly matched with two other participants. In every group of three participants there will be one player in each role (one [Lobbyist] A player, one [Lobbyist] B player, and one $C$ player [Legislator]).

You will not know the identity of the other participants you are matched with in any round, and your earnings for each round depend only on your action in that round and the actions of the participants you are matched with in that round.

\section{Targets}

At the beginning of every round, the computer will randomly select a target for each player.

Player $C$ [The Legislator's] target will be a number between -100 and 100. 
Each number is equally likely to be $C^{\prime} s$ [the Legislator's] target.

Player [Lobbyist] A's target will be less than Player C's target. The difference between [Lobbyist] A's target and C's [the Legislator's] target will be some amount between 0 and 50 units. Each amount is equally likely, and the exact amount will be selected at random in every round.

\section{Player [Lobbyist] B's target will be greater than Player C's [the Legislator's]}

target by some amount between 0 and 50 units and each amount of difference is equally likely.

For example, suppose that the computer selects 25 as Player C's [the Legislator's] target. For Player [Lobbyist] A's target, the computer will randomly select a number from -25 to 25 . Likewise, Player [Lobbyist] B's target will be a randomly selected number from 25 to 75 .

It is important to note that Player [Lobbyist] A's target and Player [Lobbyist] B's target are randomly selected by the computer independently. That is, the value of Player [Lobbyist] A's target does not affect the value of Player [Lobbyist] B's target and vice versa.

Similarly, the computer will randomly determine each player's target at the beginning of the round so that the targets in one round are selected independently of the targets in another round.

\section{Sequence of Decisions}

The sequence of decisions in every round is as follows:

1. Players [Lobbyists] A and B each find out the value of Player C's [the Legislator's] 
target and the value of their own target. (Note that Player [Lobbyist] A does not see Player [Lobbyist] B's target, nor does Player [Lobbyist] B see Player [Lobbyist] A's target.) Independently and simultaneously, Players [Lobbyists] A and B each select a message to send to Player C [the Legislator].

2. Player $C$ [The Legislator] sees the messages sent by Player [Lobbyist] A and Player [Lobbyist] B. Player C [The Legislator] then chooses an action (any number between -150 and 150). (Note that Player $C$ [the Legislator] sees both messages but none of the targets.)

\section{Payoffs}

Each player's payoff depends only on how close Player C's [the Legislator's] action is to his or her own target. More specifically, a player earns 100 points if the action is equal to his or her own target and 1 point less for each unit of difference between the action and the target. This is described by the following formula (where the straight lines indicate absolute value):

$$
\text { Player's Payoff }=100-\mid \text { Player's Target }-C^{\prime} \text { s [Legislator's] Action } \mid
$$

Note that the messages sent by Player [Lobbyist] A and Player [Lobbyist] B are not part of the payoff formula.

To illustrate, consider a few examples. Suppose you are Player [Lobbyist] A, your target is 10 and Player $C$ [the Legislator] chooses the action 40. The difference between 
your target and the action is 30, so your payoff would be 70. If Player C's [the Legislator's] target is 25 , then the difference between $C^{\prime} s$ [the Legislator's] target and the action is 15 , so $C^{\prime} s$ [the Legislator's] payoff would be 85.

Now suppose instead that Player $C$ [the Legislator] chooses the action -40. If Player [Lobbyist] A's target is 20, then the difference between A's target and the action is 60 and A's payoff would be 40. If Player [Lobbyist] B's target is 80 , then the difference between B's target and the action is 120, so B's payoff would be -20. If Player C's [the Legislator's] target is 45 , then the difference between Player C's [the Legislator's] target and the action is 85 , so Player C's [the Legislator's] payoff would be 15. (Note that it is possible for payoffs to be negative.)

\section{Sample Screens}

We will now see what the screens look like for each type of player during the experiment. 


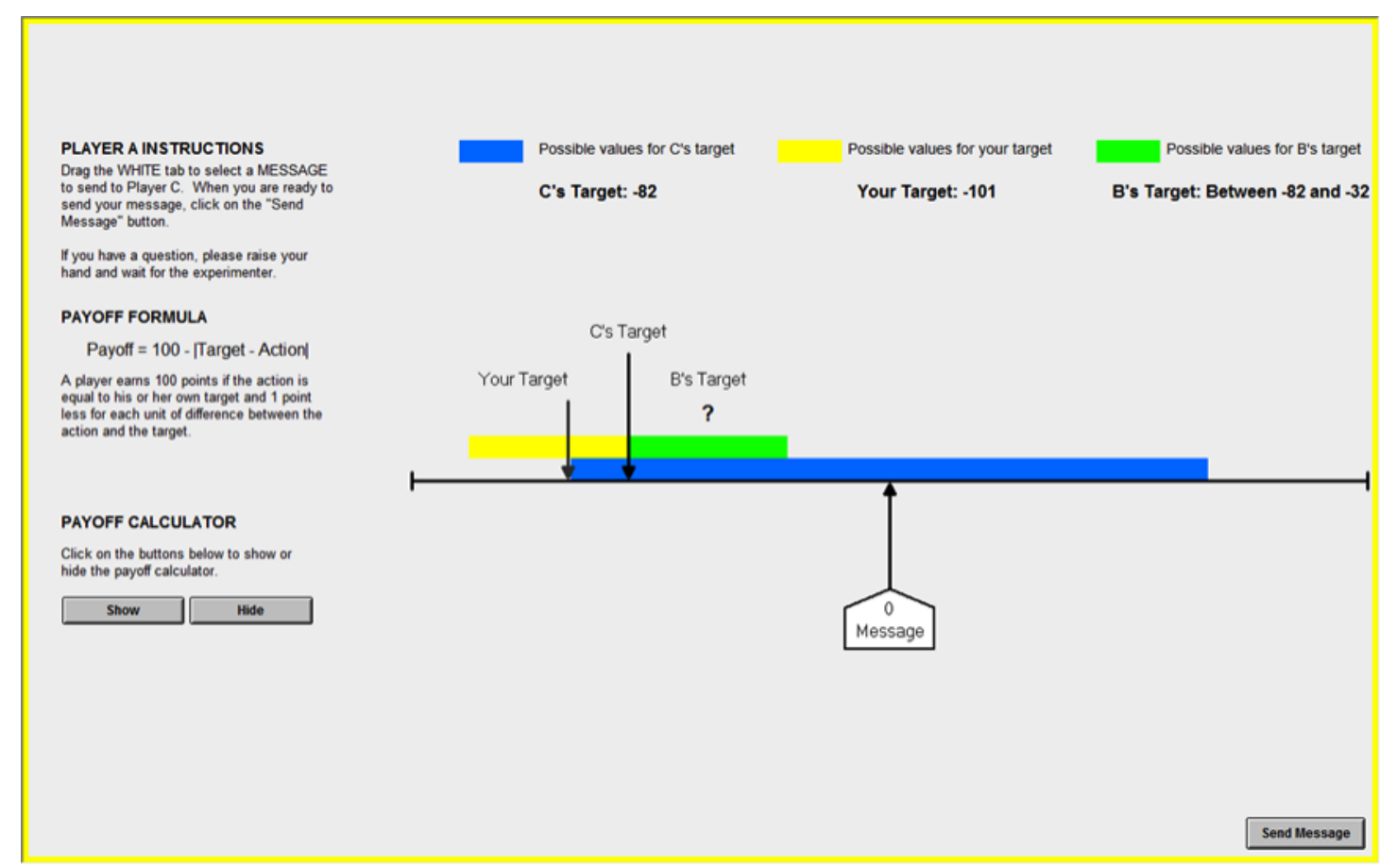

\section{Figure A1: Computer Interface Screenshot}

This is the screen that will be seen only by Player [Lobbyist] A. There is a brief set of instructions in the upper left-hand corner. A description of the payoff formula is also shown on the left side of the screen. The top of the screen shows several values: $C$ 's [the Legislator's] actual target, [Lobbyist] A's target (which is labeled "your target"), and the range of possible targets for [Lobbyist] B.

The targets are indicated graphically in the figure in the middle of the screen, which also indicates the possible range of values for each player's target. Player [Lobbyist] A chooses a message by dragging the white tab to any position along the horizontal black line. After moving the tab, it will indicate the value of the selected message.

Note that there is also a section on the left marked "payoff calculator." Click on the "Show" button to reveal an orange tab that can be used to calculate hypothetical payoffs for each possible action that Player $C$ [the Legislator] can take. If you move the orange tab to 
different positions, the bold text at the bottom of the screen changes to indicate what Player [Lobbyist] A's payoff and player C's [the Legislator] payoff would be. Note that the payoff calculator does not show B's hypothetical payoff because you do not know the value of B's target. Note also that you can hide the payoff calculator by clicking on the "hide" button.

When Player [Lobbyist] A is ready to send the message, he or she will click on the "Send Message" button in the lower right-hand corner of the screen. Feel free to move the message tab and try out the payoff calculator. When you are ready to continue, click on the "Send Message" button.

This is the screen that only Player [Lobbyist] B will see. B players [lobbyists] see this screen at the same time that the A players [lobbyists] see their screens. It is pretty much the same as Player [Lobbyist] A's screen except that B's target is known while A's is not. When you are done looking at this screen, click on the "Send Message" button to continue.

After Player [Lobbyist] A and Player [Lobbyist] B send their messages, Player C [the Legislator] will see this screen. In the upper-left corner there is again a brief set of instructions. The top of the screen shows the numerical values of the messages. The messages are also indicated graphically in the middle of the screen. To select an action, Player $C$ [the Legislator] moves the red tab to the desired location. As with the other tabs, it shows the numerical value of its location after it is moved. Note that Player $C$ [the Legislator] does not have a payoff calculator because the actual values of the targets are not known. Try moving the "Action" tab and the click on "Choose Action" button when you are ready to continue.

At the end of every round, you will see this screen, which shows you the results from 
the round-Including the actual targets of every player, both messages, and the action chosen by Player $C$ [the Legislator], and the payoffs earned by every player in your group. At the bottom of the screen, it will show the results of every previous round that you played.

\section{QUIZ INSTRUCTIONS}

To check your understanding of the decision tasks, please answer the questions below as best you can. Note that your quiz answers do not affect your earnings, and you may refer to your printed instructions as often as you like. When you are finished, feedback about the correct answers will be shown on the screen. You must attempt to answer all of the questions. If you have any further questions at this time, please raise your hand and the experimenter will come to you.

1. C's [the Legislator's] target can be any number from: [0 to 10,0 to $100,-100$ to $100,-150$ to 150$]$

2. If $C$ 's [the Legislator's] target is -40 , then [Lobbyist] A's target can be any number from: [-100 to $0,-90$ to $-40,-40$ to 10,40 to 90$]$

3. If C's [the Legislator's] target is 30 , then [Lobbyist] B's target can be any number from: [-20 to 30,0 to 50,30 to 80,50 to 100$]$

4. If you are Player $C$ [the Legislator], your target is 85 , and you choose the action 45 , how many points will you receive? [15, 40, 60, 85]

5. If you are Player [Lobbyist] A, your target is -70 , and Player $C$ [the Legislator] chooses the action 50, how many points will you receive? $[-70,-20,30,50]$

6. Suppose that you are Player [Lobbyist] B, your target is 10 and Player C's [the 
Legislator's] target is -15 . If you send the message 10 and Player $C$ [the Legislator] chooses the action 0 , how many points will you receive? $[10,15,85,90]$

7. Suppose that you are Player $C$ [the Legislator]. Player [Lobbyist] A sent you the message - 50 while Player [Lobbyist] B sent you the message 50. If you choose the action 30 and your actual target was 50, how many points will you receive? [20, 30, 70, 80]

8. In every round, will you be matched with same participants? [Yes, No] 